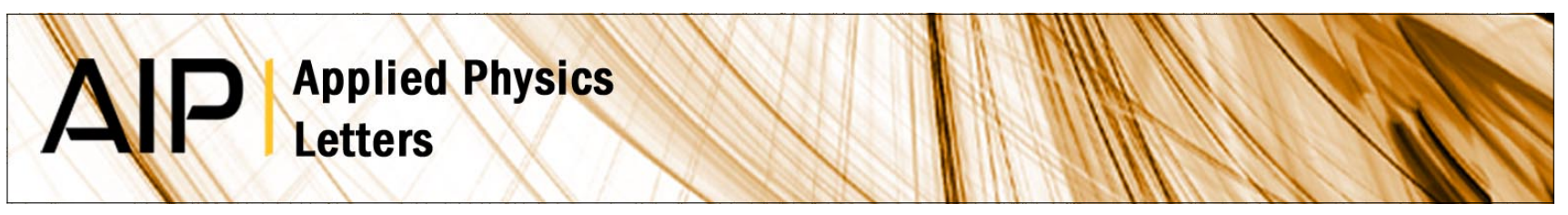

\title{
Broadband infrared emission from Er-Tm:Al2O3 thin films
}

Zhisong Xiao, R. Serna, C. N. Afonso, and I. Vickridge

Citation: Appl. Phys. Lett. 87, 111103 (2005); doi: 10.1063/1.2040005

View online: http://dx.doi.org/10.1063/1.2040005

View Table of Contents: http://apl.aip.org/resource/1/APPLAB/v87/i11

Published by the American Institute of Physics.

Additional information on Appl. Phys. Lett.

Journal Homepage: http://apl.aip.org/

Journal Information: http://apl.aip.org/about/about_the_journal

Top downloads: http://apl.aip.org/features/most_downloaded

Information for Authors: http://apl.aip.org/authors

\section{ADVERTISEMENT}

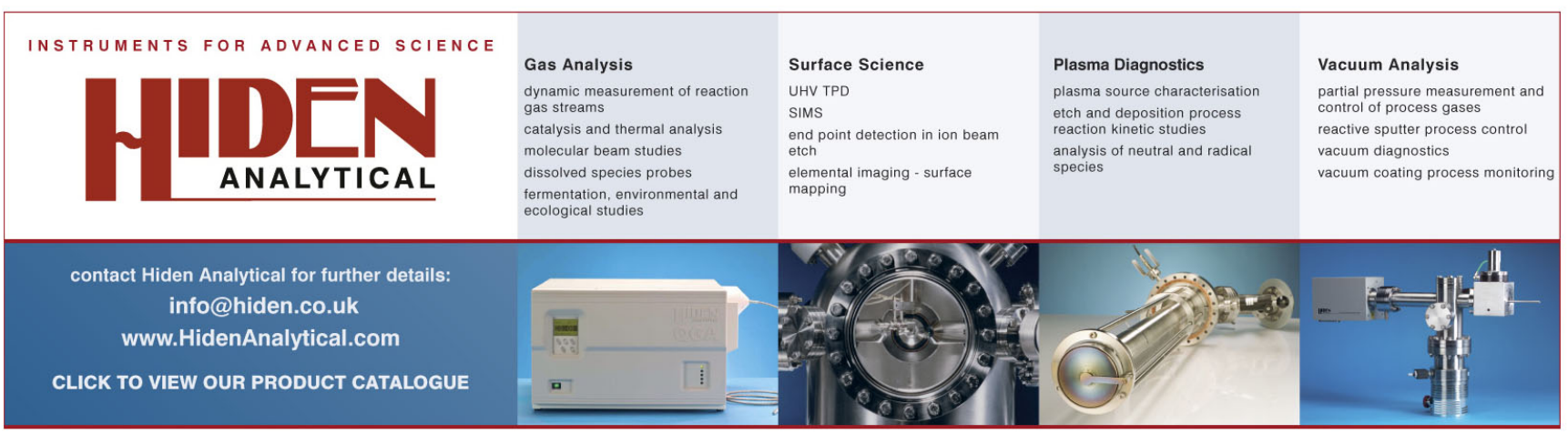




\title{
Broadband infrared emission from $\mathrm{Er}-\mathrm{Tm}: \mathrm{Al}_{2} \mathrm{O}_{3}$ thin films
}

\author{
Zhisong Xiao, R. Serna, ${ }^{a)}$ and C. N. Afonso \\ Instituto de Optica, CSIC, Serrano 121, 28006 Madrid, Spain \\ I. Vickridge \\ Institut de NanoSciences de Paris, UMR 7588 du CNRS, Universite de Paris 6 et 7, 2, Place Jussieu, \\ 75251 Paris Cedex 05, France
}

(Received 7 March 2005; accepted 15 July 2005; published online 7 September 2005)

\begin{abstract}
Thin films of amorphous aluminum oxide $\left(\mathrm{Al}_{2} \mathrm{O}_{3}\right)$ co-doped with $\mathrm{Er}^{3+}$ and $\mathrm{Tm}^{3+}$ have been synthesized by alternate pulsed laser deposition. When pumped at $794 \mathrm{~nm}$ a broad emission band over 1400-1700 nm is observed. Two peaks related to the $1540 \mathrm{~nm}$ band from $\mathrm{Er}^{3+}$ and to the 1640 $\mathrm{nm}$ band from $\mathrm{Tm}^{3+}$ are clearly distinguished. The photoluminescence intensity ratio of the 1640$1540 \mathrm{~nm}$ emissions has been controlled by modifying the Tm concentration. A spectrum with a fairly flat profile and a full width at half maximum of $230 \mathrm{~nm}$ is obtained for an Er concentration of $7.2 \times 10^{19} \mathrm{~cm}^{-3}$ and a $[\mathrm{Tm}] /[\mathrm{Er}]$ concentration ratio of 3 . It is found that the $\mathrm{Er}^{3+}$ to $\mathrm{Tm}^{3+}$ energy transfer processes play an important role in the definition of the luminescent response. The large width of the emission band and the excellent optical and thermomechanical properties of the Er-Tm co-doped $\mathrm{Al}_{2} \mathrm{O}_{3}$ signal this system as a potential candidate for the development of broadband integrated optical amplifiers. (C) 2005 American Institute of Physics. [DOI: 10.1063/1.2040005]
\end{abstract}

As a result of the rapid increase in information traffic there is a demand for broadband optical amplification beyond the conventional band of $1530-1600 \mathrm{~nm}(C+L$ band $)$ developed by erbium-doped amplifiers. In order to fully utilize the 1.4-1.7 $\mu \mathrm{m}$ low-loss band of silica-based optical fibers, the bands at 1440-1530 nm ( $S$ band) and 1625-1675 $\mathrm{nm}$ (U band) are being explored. ${ }^{1,2}$ Thulium is promising as a complement to $\mathrm{Er}^{3+}$ due to its emission bands around 1.4-1.5 $\mu \mathrm{m}$ and 1.6-1.8 $\mu \mathrm{m} .{ }^{3,4}$ Therefore the Tm doping and Er-Tm co-doping have been studied for materials suitable both for fiber ${ }^{2-4}$ and thin film ${ }^{5,6}$ devices. However, silica and most silica based glasses are not as suitable for Tm-gain devices as they are for Er ones. This is due to the fact that the transition $\mathrm{Tm}^{3+}:{ }^{3} \mathrm{H}_{4^{-}}{ }^{3} \mathrm{~F}_{4}$ leading to the emission around $1.47 \mu \mathrm{m}$ suffers appreciable multiphonon deexcitation because of the relative high maximum phonon energy $\left(\sim 1100 \mathrm{~cm}^{-1}\right)$ of these glasses. ${ }^{3,7}$ Therefore significant effort has been directed to the research of Tm-doped fluorides due to the low phonon energies of these materials $\left(\sim 580 \mathrm{~cm}^{-1}\right)$. But considering the rather poor chemical durability of most halide glasses, the development of more robust oxide glasses with sufficiently low maximum phonon energy is necessary. For this reason tellurite ${ }^{5}$ and more recently aluminate ${ }^{8}$ glasses have been explored.

The aim of this work is to demonstrate how a very broad and flat emission band in the spectral region 1400-1700 nm can be achieved from Er-Tm co-doped amorphous $\mathrm{Al}_{2} \mathrm{O}_{3}$ thin films by adequately controlling the $\mathrm{Er}$ and $\mathrm{Tm}$ concentration ratio. Amorphous aluminum oxide $\left(\mathrm{Al}_{2} \mathrm{O}_{3}\right)$ is a promising material for thin film applications due to its high thermal conductivity, excellent mechanical properties, and a wide range of transparency. In addition, amorphous $\mathrm{Al}_{2} \mathrm{O}_{3}$ shows moderate maximum phonon energy $\left(\sim 870 \mathrm{~cm}^{-1}\right){ }^{9}$ In our previous works we have shown that alternate pulsed laser deposition (PLD) from the host

\footnotetext{
${ }^{\text {a) }}$ Author to whom correspondence should be addressed; electronic mail:
} rserna@io.cfmac.csic.es
$\left(\mathrm{Al}_{2} \mathrm{O}_{3}\right)$ and dopant rare earth $(\mathrm{RE})$ targets can be used to obtain artificial structures in which the RE concentration and ion distribution are controlled. ${ }^{10,11}$

An ArF excimer laser $[\lambda=193 \mathrm{~nm}, \tau=20 \mathrm{~ns}$ full width at half maximum (FWHM), $\left.2 \mathrm{~J} \mathrm{~cm}^{-2}\right]$ was used to ablate independently the $\mathrm{Al}_{2} \mathrm{O}_{3}$ and $\mathrm{RE}$ targets. The films were designed to have a $300 \mathrm{~nm}$ total thickness. They were deposited in a multilayer-like structure by alternating the growth of $\mathrm{Al}_{2} \mathrm{O}_{3}$ layers with the deposit of $\mathrm{Er}$ and $\mathrm{Tm}$ dopants, following the sequence $\left[\mathrm{Er} /\left(\mathrm{Al}_{2} \mathrm{O}_{3} / \mathrm{Tm}\right) \times \mathbf{n} / \mathrm{Al}_{2} \mathrm{O}_{3}\right] 50$ times, where $\mathbf{n}$ is the number of Tm-doped layers inserted between two Erdoped layers. Figure 1(a) shows schematically the structure
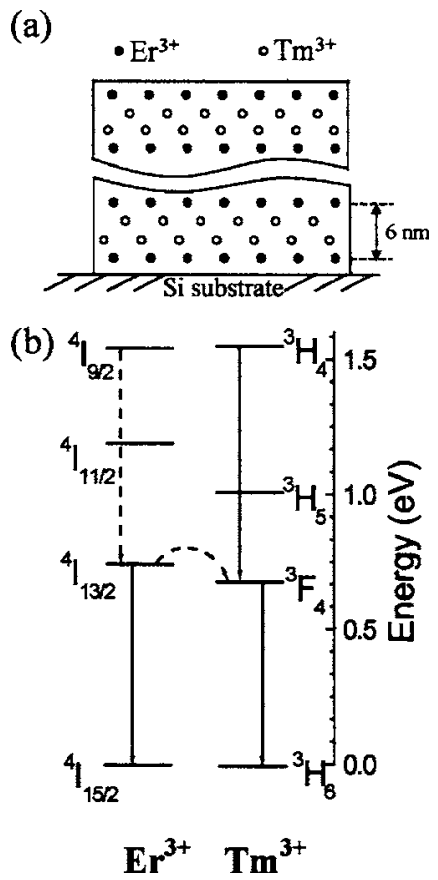

FIG. 1. (a) Schematic structure of the Er-Tm co-doped $\mathrm{Al}_{2} \mathrm{O}_{3}$ thin films with $\mathbf{n}=2$ prepared by alternate $\mathrm{PLD}$ of $\mathrm{Er}$, Tm, and $\mathrm{Al}_{2} \mathrm{O}_{3}$; (b) energy-level diagram of $\mathrm{Er}^{3+}$ and $\mathrm{Tm}^{3+}$ ions. 


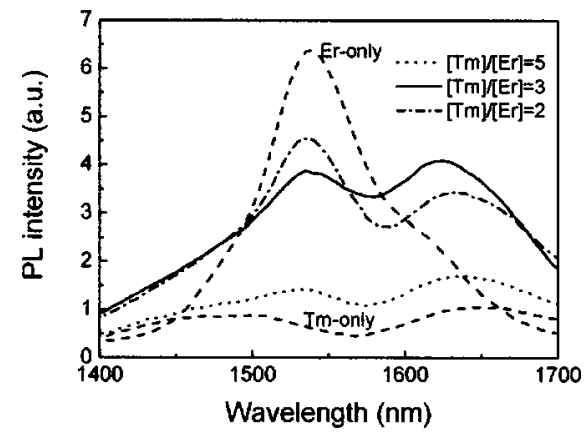

FIG. 2. PL spectra for Er-Tm co-doped $\mathrm{Al}_{2} \mathrm{O}_{3}$ films with $[\mathrm{Tm}] /[\mathrm{Er}]$ concentration ratios of 2,3, and 5. As reference the spectra for Er-only and Tm-only doped films are shown. The spectra are not corrected for the detector response.

of the films. The Er-Er in-depth separation was designed to be constant and equal to $6 \mathrm{~nm}$ both for the Er-only doped film and the Er-Tm co-doped films. This Er-Er in-depth separation was chosen since in our earlier works we have shown that this distance allows an optimum photoluminescence (PL). ${ }^{11}$ The number $\mathbf{n}$ of Tm-doped layers that were inserted between two Er-doped layers was varied from 1 to 5. In addition a Tm-only doped film was prepared with a $\mathrm{Tm}-\mathrm{Tm}$ in-depth separation of $1.5 \mathrm{~nm}$. Figure 1(b) shows a schematic representation of the energy levels for $\mathrm{Er}^{3+}$ and $\mathrm{Tm}^{3+}$. ${ }^{12}$

The RE concentration and overall in-depth profile distribution were measured by Rutherford backscattering spectrometry (RBS) using a $2.0 \mathrm{MeV} \mathrm{He}{ }^{+}$beam and a scattering angle of $165^{\circ}$. From the RBS analysis it is shown that the total projected Er areal density for the Er-only doped film is $\sim 2.2 \times 10^{15} \mathrm{~cm}^{-2}$, which is also valid for all the co-doped films. The average Er concentration in the film can be determined from the measured areal density and the measured thickness, and it is $7.2 \times 10^{19} \mathrm{~cm}^{-3}$. By changing the number $\mathbf{n}$ of Tm-doped layers, the total areal density of Tm has been varied from $2.2 \times 10^{15}$ to $1.1 \times 10^{16} \mathrm{~cm}^{-2}$, corresponding to a $\mathrm{Tm}$ to Er concentration ratios $([\mathrm{Tm}] /[\mathrm{Er}])$ of 1, 2, 3, and 5 . The average $\mathrm{Tm}$ concentration in the Er-Tm co-doped films is between $7.2 \times 10^{19} \mathrm{~cm}^{-3}(\mathbf{n}=1)$ and $3.6 \times 10^{20} \mathrm{~cm}^{-3}(\mathbf{n}=5)$, and in the Tm-only doped film is $2.9 \times 10^{20} \mathrm{~cm}^{-3}$.

After deposition the films were annealed at $650{ }^{\circ} \mathrm{C}$ for 1 $\mathrm{h}$ in air. PL measurements were performed at room temperature using a single grating monochromator (focal length 250 $\mathrm{mm}$ ) with a wavelength resolution of $8 \mathrm{~nm}$, a liquid-nitrogen cooled Ge detector, and standard lock-in techniques. The luminescence decay curves were averaged and recorded with a digital oscilloscope. Excitation spectroscopy analysis was performed using a Ti:sapphire laser (power $800 \mathrm{~mW}$ ), and the PL wavelength was fixed at $1480 \mathrm{~nm}$, corresponding to the ${ }^{3} \mathrm{H}_{4}-{ }^{3} \mathrm{~F}_{4}$ transition. Since the highest PL intensity was found for pumping at $794 \mathrm{~nm}$ in the following this wavelength was used for excitation. This result is consistent with earlier works on Tm-doped silica fibers. ${ }^{13}$ Note that this wavelength also overlaps with the absorption band of the $\mathrm{Er}^{3+}$ transition ${ }^{4} I_{15 / 2}-{ }^{4} I_{9 / 2}$ and therefore both $\mathrm{Er}^{3+}$ and $\mathrm{Tm}^{3+}$ can be pumped simultaneously at this wavelength.

Figure 2 shows the spectra for the Er-only doped, the Tm-only doped and three Er-Tm co-doped films. The spectrum for the Er-only doped film shows the characteristic $\mathrm{Er}^{3+}$ emission peak at $1540 \mathrm{~nm}$ due to the ${ }^{4} I_{13 / 2}-{ }^{4} I_{15 / 2}$ transition. The bandwidth is of $80 \mathrm{~nm}$, slightly higher than that previ-

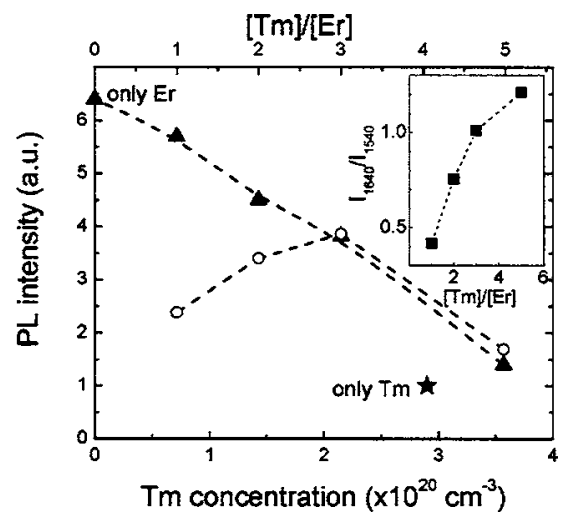

FIG. 3. PL intensity at $1540 \mathrm{~nm}(\boldsymbol{\Delta})$ and $1640 \mathrm{~nm}(\bigcirc)$ for the Er-Tm co-doped $\mathrm{Al}_{2} \mathrm{O}_{3}$ films as a function of the Tm concentration (bottom axis) and as a function of the $[\mathrm{Tm}] /[\mathrm{Er}]$ concentration ratio (top axis). The PL intensity at $1640 \mathrm{~nm}$ for the Tm-only doped film $(\star)$ is included for reference. The inset shows the 1640 to $1540 \mathrm{~nm}$ PL intensity ratio as a function of the $[\mathrm{Tm}] /[\mathrm{Er}]$ concentration ratio.

ously reported for Er-doped $\mathrm{Al}_{2} \mathrm{O}_{3} \cdot{ }^{14}$ This is in part due to the lower resolution used for these measurements, and in part to the lower annealing temperature used for this study that yields to a broadening of the transition. The spectrum for the Tm-only doped film shows two broad emission bands centered at 1480 and $1640 \mathrm{~nm}$. The $1480 \mathrm{~nm}$ peak, as discussed before, is originated from the ${ }^{3} H_{4}-{ }^{3} F_{4}$ transition. At this point it is interesting to note that for $\mathrm{Tm}^{3+}$ due to the presence of the intervening ${ }^{3} \mathrm{H}_{5}$ level that has an energy gap with the upper ${ }^{3} \mathrm{H}_{4}$ level of only about $4400 \mathrm{~cm}^{-1}$ and the desired ${ }^{3} \mathrm{H}_{4}-{ }^{3} \mathrm{~F}_{4}$ transition suffers appreciable multiphonon deexcitation when $\mathrm{Tm}$ is doped into glasses with high maximum phonon energy. ${ }^{8}$ A glass host with maximum phonon energy of $880 \mathrm{~cm}^{-1}$, corresponding to the exchange of five phonons, is expected to be suited for high luminescence quantum efficiency. ${ }^{4,6,8}$ In the case of amorphous $\mathrm{Al}_{2} \mathrm{O}_{3}$ a phonon energy spectrum has been reported with maximum phonon energy value of $870 \mathrm{~cm}^{-1},{ }^{10}$ which is consistent with the clear observation of the $1480 \mathrm{~nm}$ emission in Fig. 2. The $1640 \mathrm{~nm}$ emission can be assigned to the short wavelength band edge emission of the transition from the ${ }^{3} F_{4}$ multiplet to the ${ }^{3} H_{6}$ multiplet [Fig. 1(b)]. The emission at this wavelength has been observed in both crystalline and amorphous hosts, ${ }^{13,15,16}$ Note that the peak emission for this band is around $1800 \mathrm{~nm}$, which is out of the range of this study.

The Er-Tm co-doped films show a broad PL band in the 1.4-1.7 $\mu \mathrm{m}$ region (Fig. 2), with two peaks centered at around 1540 and $1640 \mathrm{~nm}$. This broadband is the result of the simultaneous emission of both $\mathrm{Er}^{3+}$ and $\mathrm{Tm}^{3+}$. For the co-doped films the typical $\mathrm{Er}^{3+}$ spectrum has been modified first by an intensity enhancement in the region of 1400-1500 $\mathrm{nm}$, and second by the emergence of a peak at $1640 \mathrm{~nm}$. For the film with $[\mathrm{Tm}] /[\mathrm{Er}]$ ratio of 3 the spectrum is fairly flat over all the emission range FWHM of $230 \mathrm{~nm}$. This value is quite high compared to the $90 \mathrm{~nm}$ bandwidth recently reported for an Er-Tm co-doped silica fiber. ${ }^{17}$

Figure 3 shows the evolution of the PL intensity of the two peaks as a function of the Tm concentration in the films. The PL intensity at $1540 \mathrm{~nm}$ measured for the Er-only doped film is shown on the left axis, corresponding to $[\mathrm{Tm}]=0$. The PL intensity at $1640 \mathrm{~nm}$ measured for the Tm-only doped film is shown with a star. It can be seen that for all the Er-Tm co-doped films the PL intensity at $1540 \mathrm{~nm}$ is re- 
duced with respect to that of the Er-only doped film. The decrease of the $1540 \mathrm{~nm}$ PL intensity is nearly linear with the increase of $\mathrm{Tm}$ concentration. However, the $\mathrm{Tm}^{3+} \mathrm{PL}$ intensity at $1640 \mathrm{~nm}$ for all the Er-Tm co-doped films is always higher than that of the Tm-only doped film, and it increases when the Tm concentration increases up to $2.2 \times 10^{20} \mathrm{~cm}^{-3}$, and then decreases for the highest studied concentration $[\mathrm{Tm}] /[\mathrm{Er}]=5$, and $3.6 \times 10^{20} \mathrm{~cm}^{-3}$. In Fig. 2 for this high Tm concentration there is also a reduction of the PL intensity for the emission around $1480 \mathrm{~nm}$. This PL intensity decrease is most likely due to concentration quenching originated from energy transfer between $\mathrm{Tm}^{3+}$ ions. ${ }^{18}$ The inset in Fig. 3 shows that the PL intensity ratio of the $1640 \mathrm{~nm}$ to the 1540 emission increases as the $[\mathrm{Tm}] /[\mathrm{Er}]$ ratio increases.

To understand the observed results it is necessary to assume that an energy transfer process takes place between $\mathrm{Er}^{3+}$ and $\mathrm{Tm}^{3+}$. From the energy-level diagram of $\mathrm{Er}^{3+}$ and $\mathrm{Tm}^{3+}$ ions in Fig. 1(b) it can be observed that the $\mathrm{Er}^{3+}$ level ${ }^{4} I_{13 / 2}$ has a small energy mismatch $\left(\sim 0.1 \mathrm{eV} \equiv 806 \mathrm{~cm}^{-1}\right)$ with the $\mathrm{Tm}^{3+}$ level ${ }^{3} F_{4}$ thus allowing a phonon assisted energy transfer. This implies that once the $\mathrm{Er}^{3+}$ ions are excited to the ${ }^{4} I_{9 / 2}$ they decay nonradiatively to the ${ }^{4} I_{13 / 2}$ and they can transfer the energy to the ${ }^{3} F_{4}$ level of a neighboring $\mathrm{Tm}^{3+}$, which then can decay radiatively giving rise to an enhancement of the $1640 \mathrm{~nm}$ PL intensity. Note that this $\mathrm{Er}^{3+}$ to $\mathrm{Tm}^{3+}$ energy transfer process seems to dominate even for high $\mathrm{Tm}$ concentrations, since for $[\mathrm{Tm}] /[\mathrm{Er}]=5$ the PL intensity of $\mathrm{Tm}^{3+}$ at $1640 \mathrm{~nm}$ keeps increasing at the expense of the PL intensity of $\mathrm{Er}^{3+}$ at $1540 \mathrm{~nm}$. For Er-Tm co-doped silica materials another energy transfer process has been reported, namely the energy transfer from the $\mathrm{Er}^{3+}{ }^{4} I_{13 / 2}$ level to the $\mathrm{Tm}^{3+}{ }^{3} H_{4}$ level, after which either $\mathrm{Tm}^{3+}$ ions decay radiatively to ${ }^{3} F_{4}$ resulting in an enhancement of the 1480 $\mathrm{nm}$ emission or $\mathrm{Tm}^{3+}$ ions decay nonradiatively because of the strong multiphonon effects in high phonon energy materials. ${ }^{7}$ In our present experiments the overlapping of the $1480 \mathrm{~nm}$ band with the high intensity of the $\mathrm{Er}^{3+}$-related $1540 \mathrm{~nm}$ peak prevents a quantitative assessment of a possible $1480 \mathrm{~nm}$ intensity enhancement. Finally, regarding the nature of the energy exchange between $\mathrm{Er}^{3+}$ and $\mathrm{Tm}^{3+}$, it is expected to be of dipolar nature, and therefore to follow a $R^{-6}$ dependence, where $R$ is the ions distance. At present, with the samples designed for this work, it is not straightforward to clearly separate the role played by the Er-Tm distance from the concentration effects. Work to design samples in which the $[\mathrm{Tm}] /[\mathrm{Er}]$ concentration is constant and only changes the Er-Tm layer separation is under way.

Further evidence of the $\mathrm{Er}^{3+}$ to $\mathrm{Tm}^{3+}$ energy transfer from the $\mathrm{Er}^{3+}{ }^{4} I_{13 / 2}$ level to the $\mathrm{Tm}^{3+}{ }^{3} F_{4}$ level is found when comparing the lifetimes measured for these films. The PL lifetime for the Er-Tm co-doped film with $[\mathrm{Tm}] /[\mathrm{Er}]$ $=3$ at $1540 \mathrm{~nm}$ is $0.72 \mathrm{~ms}$ and at $1640 \mathrm{~nm}$ is $0.54 \mathrm{~ms}$. For the Er-only doped film the PL lifetime at $1540 \mathrm{~nm}$ is $3.42 \mathrm{~ms}$, and for the Tm-only doped film the PL lifetime at $1640 \mathrm{~nm}$ is $0.29 \mathrm{~ms}$. Therefore in the co-doped film the lifetime of the
$\mathrm{Tm}^{3+}$ related transition has increased by almost a factor of 2 , whereas that of the $\mathrm{Er}^{3+}$ has been reduced by almost a factor of 5 as a result of the $\mathrm{Er}^{3+}$ to $\mathrm{Tm}^{3+}$ energy transfer process. Therefore $\mathrm{Er}^{3+}$ is acting as a sensitizer for $\mathrm{Tm}^{3+}$ as well as a light emitter itself.

In conclusion, we have prepared Er-Tm co-doped amorphous $\mathrm{Al}_{2} \mathrm{O}_{3}$ thin films by PLD that under $794 \mathrm{~nm}$ excitation show a broad emission band for the wavelength range of $1.4-1.7 \mu \mathrm{m}$. It is shown that for a $[\mathrm{Tm}] /[\mathrm{Er}]$ ratio of $3 \mathrm{a}$ fairly flat band with a FWHM of $230 \mathrm{~nm}$ is obtained. The band is composed of the 1480 and $1640 \mathrm{~nm}$ emissions from $\mathrm{Tm}^{3+}$, and the $1540 \mathrm{~nm}$ emission from $\mathrm{Er}^{3+}$. The results evidence energy transfer from $\mathrm{Er}^{3+}$ to $\mathrm{Tm}^{3+}$ which can be used to tailor the PL response. Further studies are necessary to optimize the concentration and distribution of the dopants in order to tune the energy exchange interaction between ions and to obtain higher PL efficiencies. The obtained results suggest that the $\mathrm{Er}-\mathrm{Tm}: \mathrm{Al}_{2} \mathrm{O}_{3}$ system is a potential candidate for the development of integrated waveguide broad gain devices.

This work was supported by CICYT (Spain) under the TIC2002-03235 Project, by the collaborative structure around SAFIR (CNRS and MENRT, France), and Z. X. acknowledges a fellowship from MEC (SB2002-0013, Spain).

${ }^{1}$ J. Kani, K. Hattori, M. Jinno, S. Aisawa, T. Sakamoto, and K. Oguchi, Electron. Lett. 35, 321 (1999).

${ }^{2}$ S. Tanabe, N. Sugimoto, S. Ito, and T. Hanada, J. Lumin. 87, 670 (2000).

${ }^{3}$ T. Komukai, T. Yamamoto, T. Sugawa, and Y. Miyajima, IEEE J. Quantum Electron. 31, 1880 (1995).

${ }^{4}$ S. L. Oliveira, S. M. Lima, T. Catunda, L. A. Nunes, J. H. Rohling, A. C. Bento, and M. L. Baesso, Appl. Phys. Lett. 84, 359 (2004).

${ }^{5}$ S. Y. Seo, J. H. Shin, B. S. Bae, N. Park, J. J. Penninkhof, and A. Polman, Appl. Phys. Lett. 82, 3445 (2003).

${ }^{6}$ K. Watanabe, H. Tamaoka, M. Fujii, and S. Hayashi, J. Appl. Phys. 92, 4001 (2002).

${ }^{7}$ M. Naftaly, S. Shen, and A. Jha, Appl. Opt. 39, 4979 (2000).

${ }^{8}$ B. G. Aitken, M. J. Dejneka, and M. L. Powley, J. Non-Cryst. Solids 349, 115 (2004)

${ }^{9}$ M. B. Lee, J. H. Lee, B. G. Frederick, and N. V. Richardson, Surf. Sci. 448, L207 (2000).

${ }^{10}$ A. Suarez-Garcia, R. Serna, M. J. de Castro, C. N. Afonso, and I. Vickridge, Appl. Phys. Lett. 84, 2151 (2004).

${ }^{11}$ R. Serna, M. J. de Castro, J. A. Chaos, A. Suarez-Garcia, C. N. Afonso, M. Fernandez, and I. Vickridge, J. Appl. Phys. 90, 5120 (2001).

${ }^{12}$ W. T. Carnall, P. R. Fields, and K. Rajnak, J. Chem. Phys. 49, 4424 (1968).

${ }^{13}$ D. C. Hanna, R. M. Percival, R. G. Smart, A. C. Tropper, Opt. Commun. 75, 283 (1990).

${ }^{14}$ G. N. van den Hoven, E. Snoeks, A. Polman, J. W. M. van Uffelen, Y. S. Oei, and M. K. Smit, Appl. Phys. Lett. 62, 3065 (1993).

${ }^{15}$ T. Tsuboi, J. Electrochem. Soc. 147, 1997 (2000).

${ }^{16}$ M. C. Pujol, F. Güel, X. Mateos, Jna. Gavaldá, R. Solé, J. Massons, M. Aguiló, F. Díaz, G. Boulon, and A. Brrenier, Phys. Rev. B 66, 144304 (2002).

${ }^{17}$ H. Jeong, K. Oh, S. R. Han, and T. F. Morse, Chem. Phys. Lett. 367, 507 (2003).

${ }^{18}$ J. R. Lincoln, W. S. Brocklesby, F. Cusso, J. E. Townsend, A. C. Tropper, and A. Pearson, J. Lumin. 50, 297 (1991). 